\title{
Spiritual Coping of Emergency Department Nurses and Emergency Medical Services Staff During the COVID-19 Pandemic in Iran: An Exploratory Study
}

\author{
Aghil Habibi Soola ${ }^{1} \cdot$ Naser Mozaffari $^{1} \cdot$ Alireza Mirzaei $^{2} \mathbb{D}$
}

Accepted: 8 February 2022 / Published online: 27 February 2022

(C) The Author(s), under exclusive licence to Springer Science+Business Media, LLC, part of Springer Nature 2022

\begin{abstract}
Emergency department (ED) nurses and emergency medical services (EMS) staff have been recently exposed to high levels of stress due to the new Coronavirus (COVID-19) pandemic. This increased stress level may influence the physical and mental health of ED nurses and EMS staff and the quality of caregiving to the patients. A spiritual coping approach is one of the most commonly used strategies to help healthcare workers manage stressful events or situations. This study explores the spiritual coping (positive or negative) among ED nurses and EMS staff during the COVID-19 pandemic. A descriptive cross-sectional study was performed on 494 ED/EMS nurses in Ardabil Province in the northwest of Iran, using a convenience sampling method. The spiritual coping questionnaire (SCQ) was used to assess spiritual coping in the subjects. The results of this study showed that ED nurses and EMS staff generally used positive spiritual coping methods to reduce stress during the COVID-19 pandemic. Multiple linear regression indicated that workplace $(\beta=0.22, p<0.001)$, service location $(\beta=0.16, p<0.001)$, and type of employment $(\beta=-0.13, p=0.012)$ were significant predictors of positive spiritual coping, and older age $(\beta=0.13, p=0.045)$, overtime work $(\beta=0.12, p=0.01)$, and marital status $(\beta=-0.12, p=0.021)$ were predictors of negative spiritual coping. Our findings indicated that positive religious behavior was the main spiritual coping strategy used by healthcare workers. The findings could help emergency nurse managers to propose future strategies to minimize stress based on the use of spiritual coping strategies and provide time and facilities to pray.
\end{abstract}

Keywords Coping behaviors $\cdot$ Emergency department $\cdot$ Nurses $\cdot$ Emergency medical services $\cdot$ Staff $\cdot$ Workplace and COVID-19

Alireza Mirzaei

alirezamirzaei9015@gmail.com

Extended author information available on the last page of the article 


\section{Introduction}

During 2020, one of the most widespread global crises occurred given COVID19 (Huang et al., 2020). As a consequence of this critical situation, emergency nurses including emergency department (ED) nurses and emergency medical services (EMS) nurses are being faced with COVID-19 patients (Rajabipoor Meybodi \& Mohammadi, 2021; shakeri et al., 2019). Accordingly, these healthcare workers experience high-stress levels that may weaken their physical health and mental health. Using appropriate strategies given the dealing with highly stressful situations and complex work conditions of COVID-19 epidemics are necessary issues. (Rajabipoor Meybodi \& Mohammadi, 2021). The consequences caused by the COVID-19, in addition to creating various questions in the religious community, have led researchers and those interested in the field of "spiritual health" to explain the dimensions of development and promotion of spiritual health in society (Huang et al., 2020).

Recent studies have suggested religious and spiritual strategies as a tool to cope with psychological and physical challenges (Koenig, 2020). Religious coping involves enjoying a spiritual and moral relationship with God through praying or linking with God in times of crisis (Pargament et al., 2011). Spirituality differs from other concepts such as humanism, values, morality, and mental health due to its relationship to the sacred. In addition, spirituality has a dynamic character, because it can develop, change forms, or be invisible. Charzyńska defines spiritual coping as an attempt to overcome stressors based on immaterial resources (what is transcendent), including both positive and negative coping strategies (Charzyńska, 2015).

Positive spiritual coping involves cognitive and behavioral efforts to resolve difficult situations, which include the following domains: Personal (such as goal search, sense and meaning, focus on one's inner life, try to overcome one's weaknesses, search for peace, and inner harmony), social (such as establishing and maintaining deep and valuable relationships with others, paying attention to moral values, fair treatment with people, taking care of others, love, sympathy, and compassion for others), environmental (such as understanding harmony and regularity available in nature), and religious (such as maintaining a strong relationship with the God/superior power) (Charzyńska, 2015).

In contrast, negative spiritual coping makes it impossible for an individual to draw strength from spiritual resources, blocks the pursuit of sense and meaning in life, and hinders its growth, "upward movement" and going beyond what is material. Negative spiritual coping also includes personal (such as denying purpose and meaning of life, emphasizing on weaknesses and limitations, focusing on one's mistakes or violations), social (such as understanding people as inherently selfish and self-interested creatures), and religious (such as inner religious challenge manifesting itself as hatred of the God/supreme power, his blaming and denial) domains (Charzyńska, 2015; Ibrahim et al., 2020; Khodayarifard et al., 2019).

A recent study in Brazil showed a significant role of religiosity and spirituality in reducing fear, sadness, and anxiety about the COVID-19 pandemic and, 
consequently, social isolation (Lucchetti et al., 2020). The results of a study conducted in Iran showed that religious belief helps veterans to accept the effect of mustard gas poisoning on their lives and to adapt their lifestyle based on it, to participate in social-religious activities, to feel social support, and hope for the future (Hassankhani et al., 2010). Praying of Muslim nurses reduces their job stress and increases their well-being and life satisfaction (Achour et al., 2019, 2021). Employees who have low spirituality and morale in the workplace, also suffer from higher job abandonment, burnout, and stress (Doraiswamy \& Deshmukh, 2015).

Praying (praise) significantly reduces the likelihood of the manifestation of post-traumatic stress disorder (PTSD) symptoms in the COVID-19 pandemic (Szałachowski \& Tuszyńska-Bogucka, 2021). During the pandemic, people who had low levels of spirituality had increased anxiety compared to those with higher levels of spirituality (Rias et al., 2020). A study conducted in the Philippines showed that Dungaw praying had a significant effect on coping with the COVID-19 among Catholic priests (del Castillo et al., 2021).

In the study by Ibrahim et al., the majority of health workers in emergency and critical care settings had positive religious coping as the highest stress decreasing approach. The authors concluded that spiritual coping behaviors are common in healthcare settings that still has a deficiency of integration of spiritual components in its physical infrastructure, health policy, and management (Ibrahim et al., 2020). Proper understanding and implementation of spiritual coping strategies by health managers can help to reduce the stress of health workers in the COVID-19 crisis. In this study, we aimed to explore the spiritual coping (positive and negative) of Iranian emergency department nurses and emergency medical services staff during the COVID-19 pandemic.

\section{Materials and Methods}

\section{Study Design}

A descriptive correlational study was performed on ED nurses and EMS staff using cross-sectional survey methodology in Ardabil, an ancient city in the northwest of Iran and capital of Ardabil Province. The study was performed in the first quarter of 2021. The inclusion criteria were (1) having at least 6 months of clinical work experience in hospital ED or EMS, (2) not being on vacation for at least one week before completing the questionnaire, and (3) having no history of mental illness through self-declaration. Incomplete questionnaires were excluded from the study. Before sampling by the researcher, a brief introduction of the research and its purpose was provided to the research subjects and informed written consent was obtained from all participants. Then, nurses proceeded to complete the questionnaires in a self-declaration manner. The paper version of the questionnaire was distributed among 821 nurses who met the inclusion criteria. Finally, 494 people completed the questionnaire. 


\section{Data Collection Tools}

Data collection tools included demographic information form and spiritual coping questionnaire (SCQ) developed by Charzyńska.

\section{Demographics}

The form included questions related to age, gender, working experience, city of service location, marital status, level of education, workplace, type of employment, income level, rank, and average overtime work per month.

\section{Spiritual Coping Questionnaire (SCQ)}

The SCQ developed by Charzyńska (2015) was used to measure spiritual coping with stress. The tool consists of 32 questions divided into two main scales and seven subscales: positive and negative spiritual coping. The positive spiritual coping scale includes four subscales: personal (4 items, for example; I was trying to find a reason for what happened), social (6 items, for example; I empathized with suffering from others), environmental ( 5 items, for example; I looked for closeness to nature), and religious (6 items, for example; in my relationship with God/higher power, I looked for the strength to live). Negative spiritual coping scale involves three subscales: personal (4 items, for example; I convinced myself that my life has no purpose), social (4 items, for example; I tried to prove to others that I am selfish), and religious (3 items, for example, I blamed the God for what had happened in my life). The Cronbach's alpha coefficient positive and negative spiritual coping scales were 0.92 and 0.82 , respectively, in the study by Charzyńska (Charzyńska, 2015). The following guidelines were provided in the current study before responding to the questionnaire items: please specify how each of these statements describes what you have done over the past 4 weeks during exposure to this stressful situation. Answers were scored on a 6-point Likert scale based on a standardized questionnaire in Persian (Khodayarifard et al., 2019) (from $1=$ completely inaccurate to $6=$ completely accurate). The scores of each of the seven subscales were calculated with mean answers to the questions specific to each subgroup (ranging from 1 to 6). Cronbach's alpha coefficients for the two main scales (positive and negative spiritual coping) of the SCQ in the study by Khodayarifard et al., (Khodayarifard et al., 2019) was 0.84 and 0.90 and in the present study was 0.94 and 0.93 , respectively.

The participants who met the inclusion criteria were fully informed about the study's protocol. The study protocol was approved by the Ethics Committee of Ardabil University of Medical Sciences (IR. ARUMS REC.1399.459). Written consent was obtained from all participants. Participation in the study was absolutely voluntary, and participants were ensured about the confidentiality of their information. The anonymous questionnaires were distributed to EMS staff and ED nurses. 


\section{Statistical Analysis}

The data were evaluated using SPSSv14 statistical software. Demographic characteristics, level of positive and negative spiritual coping, and subgroups in ED nurses and EMS staff were analyzed using descriptive statistics (mean, standard deviation, frequency, and percentage). The relationship between demographic characteristics and positive spiritual and negative spiritual coping of ED nurses and EMS staff was evaluated using "Pearson correlation coefficient", Independent-Samples t-test, and analysis of variance (ANOVA). Predictors of positive and negative spiritual coping of ED nurses and EMS staff were investigated using multiple linear regression.

\section{Results}

The overall response rate of the study was $60.1 \%$ (494/821). Among the study participants, $55.5 \%$ were under 30 years of age, and $74.3 \%$ had less than 10 years of working experience. It was found that $60.1 \%$ of the participants were male, $58.9 \%$ were married, $83.8 \%$ had a bachelor's degree, and $57.7 \%$ were working in a hospital ED. The service location of 53.8\% of the participants was in Ardabil City, and 267 people $(54.0 \%)$ were officially employed. $51.8 \%$ of participants (256 people) had a mean annual income of 2200 \$2800 per year. One hundred sixty-four (164) participants had overtime work between 41 and $80 \mathrm{~h}$ during the last working month (Table 1).

Findings (Table 2) showed that variables of age, gender, education level, service location, workplace, type of employment, and overtime work had a statistically significant relationship with positive spiritual coping. Also, variables of age, workplace, annual income level, and overtime had a statistically significant relationship with negative spiritual coping of ED nurses and EMS staff $(p<0.05)$. Refer Appendix 1 for greater detail regarding Table 2

The results obtained from multiple regression model to predict positive and negative spiritual coping of ED nurses and EMS staff based on demographic variables are shown in Table 3. The results showed that variables of workplace $(\beta=0.22$, $\left.R^{2}=0.11, p<0.001\right)$, service location $\left(\beta=0.16, R^{2}=0.11, p<0.001\right)$, and type of employment $\left(\beta=-0.13, R^{2}=0.11, p=0.012\right)$ were significant predictors of positive spiritual coping, and high age $\left(\beta=0.13, R^{2}=0.06, p=0.045\right)$, overtime $(\beta=0.12$, $\left.R^{2}=0.06, p=0.001\right)$, and marital status $\left(\beta=-0.12, R^{2}=0.06, p=0.021\right)$ were predictors of negative spiritual coping. ${ }^{1}$

\footnotetext{
1 Refer to Appendix 1 for greater detail regarding Table 2 scores.
} 
Table 1 Demographic characteristics $(n=494)$

\begin{tabular}{|c|c|c|c|}
\hline Demographic & Variables & $N$ & $(\%)$ \\
\hline \multirow[t]{3}{*}{ Age group } & $\leq 29$ years & 274 & 55.5 \\
\hline & 30-39 years & 171 & 34.6 \\
\hline & $\geq 40$ years & 49 & 9.9 \\
\hline \multirow[t]{3}{*}{ Work experience } & $\leq 9$ years & 367 & 74.3 \\
\hline & 10-18 years & 114 & 23.1 \\
\hline & $\geq 19$ years & 13 & 2.6 \\
\hline \multirow[t]{2}{*}{ Gender } & Male & 297 & 60.1 \\
\hline & Female & 197 & 39.9 \\
\hline \multirow[t]{2}{*}{ Marital status } & Single & 203 & 41.1 \\
\hline & Married & 291 & 58.9 \\
\hline \multirow[t]{2}{*}{ Educational levels } & Associate & 80 & 16.2 \\
\hline & Bachelor's & 414 & 83.8 \\
\hline \multirow[t]{2}{*}{ Service location } & Ardebil city & 266 & 53.8 \\
\hline & Countryside & 228 & 46.2 \\
\hline \multirow[t]{2}{*}{ Workplace } & ED & 285 & 57.7 \\
\hline & EMS & 209 & 42.3 \\
\hline \multirow[t]{3}{*}{ Type of employment } & Commitment & 159 & 32.2 \\
\hline & Contractual & 68 & 13.8 \\
\hline & Employed & 267 & 54.0 \\
\hline \multirow[t]{4}{*}{ Annual income (US\$) } & $1600-2200$ & 44 & 8.9 \\
\hline & $2200-2800$ & 256 & 51.8 \\
\hline & $2800-3600$ & 168 & 34.0 \\
\hline & $>3600$ & 26 & 5.3 \\
\hline \multirow[t]{4}{*}{ Overtime } & $\leq 40$ & 114 & 23.1 \\
\hline & $41-80$ & 164 & 33.2 \\
\hline & $81-120$ & 139 & 28.1 \\
\hline & $>120$ & 77 & 15.6 \\
\hline
\end{tabular}

\section{Discussion}

The current study was conducted to explore spiritual coping and predictors of positive and negative spiritual coping based on demographic characteristics among ED nurses and EMS staff working in Educational and medical centers in Ardabil province (in Northwestern Iran).

\section{Predictors of Positive Spiritual Coping}

The results of multiple regression showed that the workplace was a predictor of positive spiritual coping, which was consistent with the findings from previous studies (Ozbasaran et al., 2011; Ronaldson et al., 2012). Findings from these studies show that nurses working in palliative care wards, pediatric, and psychiatric 
Table 2 Comparison of total mean scores of Positive spiritual coping and Negative spiritual coping in terms of socio-demographic data of Emergency Department Nurses and Emergency Medical Services staff $(n=494)$

\begin{tabular}{|c|c|c|c|c|c|}
\hline \multirow[t]{2}{*}{ Variables } & & \multicolumn{2}{|c|}{ Positive spiritual coping } & \multicolumn{2}{|c|}{ Negative spiritual coping } \\
\hline & & Mean (SD) & $p$ Value & Mean (SD) & $p$ Value \\
\hline \multirow[t]{3}{*}{ Age group } & $\leq 29$ years & $4.79(0.71)$ & $F=4.379$ & $2.65(1.14)$ & $F=4.375$ \\
\hline & 30-39 years & $4.52(0.78)$ & & $2.99(1.16)$ & \\
\hline & $\geq 40$ years & $4.76(0.93)$ & $p=0.005$ & $2.83(1.10)$ & $p=0.005$ \\
\hline \multirow[t]{3}{*}{ Work experience } & $\leq 9$ years & $4.70(0.76)$ & $F=1.073$ & $2.76(1.14)$ & $F=1.154$ \\
\hline & $10-18$ years & $4.65(0.81)$ & & $2.89(1.15)$ & \\
\hline & $\geq 19$ years & $4.98(0.58)$ & $p=0.343$ & $3.14(1.22)$ & $p=0.316$ \\
\hline \multirow[t]{2}{*}{ Gender } & Male & $4.76(0.71)$ & $t=2.434$ & $2.72(1.14)$ & $t=-1.852$ \\
\hline & Female & $4.59(0.85)$ & $p=0.015$ & $2.91(1.15)$ & $p=0.065$ \\
\hline \multirow[t]{2}{*}{ Marital status } & Single & $4.73(0.73)$ & $t=0.784$ & $2.85(1.19)$ & $t=0.794$ \\
\hline & Married & $4.67(0.80)$ & $p=0.433$ & $2.76(1.11)$ & $p=0.428$ \\
\hline \multirow[t]{2}{*}{ Educational levels } & Associate & $4.89(0.70)$ & $t=2.477$ & $2.66(1.22)$ & $t=-1.149$ \\
\hline & Bachelor's & $4.66(0.78)$ & $p=0.014$ & $2.82(1.13)$ & $p=0.251$ \\
\hline \multirow[t]{2}{*}{ Service location } & Ardebil city & $4.54(0.81)$ & $t=-4.843$ & $2.88(1.14)$ & $\mathrm{t}=1.744$ \\
\hline & Countryside & $4.87(0.68)$ & $p=0.000$ & $2.70(1.15)$ & $p=0.082$ \\
\hline \multirow[t]{2}{*}{ Workplace } & ED & $4.54(0.82)$ & $t=-5.097$ & $2.91(1.13)$ & $t=2.524$ \\
\hline & EMS & $4.90(0.65)$ & $p=0.000$ & $2.64(1.15)$ & $p=0.012$ \\
\hline \multirow[t]{3}{*}{ Type of employment } & Commitment & $4.85(0.70)$ & $F=5.152$ & $2.71(1.21)$ & $F=0.745$ \\
\hline & Contractual & $4.58(0.70)$ & & $2.80(1.21)$ & \\
\hline & Employed & $4.63(081)$ & $p=0.006$ & $2.85(1.12)$ & $p=0.475$ \\
\hline \multirow[t]{4}{*}{ Annual income (US\$) } & $1600-2200$ & $4.65(0.78)$ & $F=1.587$ & $2.81(1.05)$ & $F=4.107$ \\
\hline & $2200-2800$ & $4.76(0.73)$ & & $2.68(1.17)$ & \\
\hline & $2800-3600$ & $4.60(0.54)$ & $p=0.192$ & $2.87(1.11)$ & $p=0.007$ \\
\hline & $>3600$ & $4.74(0.65)$ & & $3.46(1.11)$ & \\
\hline \multirow[t]{4}{*}{ Overtime } & $<40$ & $4.87(0.67)$ & $F=3.197$ & $2.50(1.13)$ & $F=3.439$ \\
\hline & $41-80$ & $4.59(0.90)$ & & $2.88(1.17)$ & \\
\hline & $81-120$ & $4.65(0.68)$ & $p=0.023$ & $2.90(1.09)$ & $p=0.017$ \\
\hline & $>120$ & $4.72(0.72)$ & & $2.87(1.15)$ & \\
\hline
\end{tabular}

wards had a greater spiritual understanding than nurses working in other hospital wards. Additionally, their findings suggested that the higher perception of nurses in the field of spirituality were related to spiritual education and wider use of communication and therapeutic skills (Ozbasaran et al., 2011; Ronaldson et al., 2012). Perhaps, the location and the nature of providing services in EMS are such that counseling or the spiritual relationship between nurses and patients in a more desirable way is possible. Also, since EMS staff has a relatively lower workload and better rest and praying place than ED nurses in hospitals in Ardabil Province, they use higher positive spiritual coping strategies. 
Table 3 Multiple regression analysis for Positive spiritual coping and Negative spiritual coping total

\begin{tabular}{|c|c|c|c|c|c|c|}
\hline \multirow[t]{2}{*}{ Variables } & \multicolumn{3}{|c|}{ Positive spiritual coping total } & \multicolumn{3}{|c|}{ Negative spiritual coping total } \\
\hline & Beta & Sig & & Beta & Sig & \\
\hline (Constant) & & $p<0.001$ & & & $p<0.001$ & \\
\hline Age (30-39 years) & -0.096 & 0.149 & & 0.137 & 0.045 & \\
\hline Work experience & 0.121 & 0.059 & $R^{2}=0.113$ & -0.019 & 0.771 & $R^{2}=0.064$ \\
\hline Gender & 0.034 & 0.561 & $\operatorname{Adj} R^{2}=0.094$ & 0.063 & 0.297 & $\operatorname{Adj} R^{2}=0.044$ \\
\hline Marital status (married) & 0.048 & 0.352 & $F=6.132$ & -0.122 & 0.021 & $F=3.28$ \\
\hline Educational levels & -0.007 & 0.889 & $p<0.001$ & -0.013 & 0.791 & $p<0.001$ \\
\hline $\begin{array}{l}\text { Service location (Country- } \\
\text { side) }\end{array}$ & 0.165 & $p<0.001$ & & -0.042 & 0.361 & \\
\hline Workplace (EMS) & 0.227 & $p<0.001$ & & -0.107 & 0.086 & \\
\hline $\begin{array}{l}\text { Type of employment } \\
\text { (Employed) }\end{array}$ & -0.133 & 0.012 & & 0.014 & 0.800 & \\
\hline Annual income & -0.010 & 0.829 & & 0.087 & 0.078 & \\
\hline Overtime $(81-120)$ & -0.083 & 0.081 & & 0.127 & 0.010 & \\
\hline
\end{tabular}

Service location was also found to be a predictor of positive spiritual coping. The staff working in the educational and medical centers in Ardabil countryside have less difficulty and workload which, might explain the relationship between service location and positive spiritual coping. The results of the study analysis showed that the participants' employment status had a significant inverse relationship with positive spiritual coping. In this study, the official participants who employed positive spiritual coping strategies obtained lower scores than the employees with commitment and contractual employment status, which was consistent with the study results by Farshadnia et al. (2020). Perhaps the employees with commitment and contractual employment status are at the beginning of the career path and have more patience consequently are inclined to use positive spiritual coping mechanisms.

\section{Predictors of Negative Spiritual Coping}

The results of multiple regression showed that age was one of the predictors of negative spiritual coping, and young nurses used less negative spiritual coping than older ones. Conversely, old nurses used less positive spiritual coping than younger nurses, which was in-line with the results of the previous studies (Albaqawi et al., 2019; Ozbasaran et al., 2011). In our study, most respondents were young. In youth, holistic thinking is dominant so that young people begin to become aware of the complexities of life. This stage is also a phase where people recognize the whole human being and contribute to healing processes, including the spiritual needs of patients. Since the nursing profession is very difficult and very tedious, these staff should be encouraged to express their concerns and receive mental support through religious and spiritual counselors.

The results showed that marital status was one of the predictors of negative spiritual coping. In the current study, married participants obtained lower scores on the 
negative spiritual coping scale than single participants. Marriage protects against adverse health outcomes by modifying health behaviors and developing social networks arising from the union. Regarding the mutual effect of various dimensions of the couple's health on each other, married people are expected to have higher levels of spiritual health (Farshadnia et al., 2020; Robards et al., 2012). The results of the study showed that overtime work was a predictor of negative spiritual coping. Findings from Ozbasaran et al. (2011) indicated that increased workload and lack of time are obstacles to the understanding of spirituality by nurses. This finding can be evaluated because nurses with much overtime work have more workload and, due to fatigue and lack of concentration, have less time to perform spiritual activities (e.g., praying), leading to decreased attention to spirituality. Challenges related to health care and nursing management require new perspectives, such as those resulting from spiritual leadership. In times of global challenge, when nurses are at the forefront, there is a need to develop organizational environments promoting wellbeing and a sense of dignity, hope, happiness, and meaning (Ribeiro et al., 2021).

\section{Spiritual Coping in Critical Situations}

Participants suggested positive religious coping as the primary coping method and positive social, personal, and environmental coping as occupational stress strategies. However, they did not score high on the negative spiritual coping scale. In the study by Ibrahim et al. (2020), the ED and critical care nurses obtained the highest scores n positive religious, personal, social, and environmental coping scales. Conversely, they did not obtain a high score in negative spiritual coping scales, which was consistent with the results of our study, showing that most ED nurses and EMS staff perform a positive spiritual approach for coping with occupational stress, where positive religious coping (feeling God's presence in everyday life, focusing on God's care for His servants, focusing on God's love for His servants, relying on the God in trouble, finding peace in praying) is dominant. Muslims account for the majority of Iran's population; as religion and culture are intertwined with their lifestyle, religious beliefs play an important role in their lives, especially in stressful and critical situations (Hassankhani et al., 2010). A survey in Iran showed that religious beliefs, such as reading the Holy book, praying, and trusting in God, are effective methods used by clinical nurses to reduce stress (Jannati et al., 2011).

Findings from DeRossett et al. (2021) indicated that religious coping is one of the potential strategies for managing stressors. Positive religious coping is associated with better physical and mental health outcomes, while negative religious coping is associated with increased stress and anxiety. Also, according to the results of the previous studies, nurses have suggested spiritual coping as one of their strategies for coping with job stress. This approach, manifesting itself as spiritual practices, such as saying prayers or reciting the Holy book, can include attributes like seeking help from God and a sense of support for a superior force taken by nurses in various work situations. Spiritual coping help to alleviate stress (Eslami Akbar et al., 2015; Habibian et al., 2015). People who suffer from health anxiety choose religious coping (Mahmood et al., 2021). We conclude that it is vital to consider the role of 
religion and spirituality during epidemic anxiety. In order to mental health promotion interventions during pandemics, there are concepts for counselors, emergency managers, and researchers that integrate religious coping strategies in the workplace.

The results of a study conducted on nurses of Korean elderly hospitals showed that spiritual health significantly reduces their stress (Yang \& Shin, 2016). Findings from del Castillo et al. (2021) indicated that Filipino Catholics used religion as a source of coping in turbulent times of the COVID-19 pandemic. Also, Chow et al. (2021) demonstrated that positive religious coping played an effective role in reducing anxiety and depression among health staff engaged in fighting against the COVID-19 pandemic. Praying has been shown to play a protective role against stress and reduce symptoms of PTSD (Bentzen, 2020; Szałachowski \& TuszyńskaBogucka, 2021). Findings from Achour et al., $(2019,2021)$ confirmed that praying moderates the relationship between job stress and spiritual well-being and is an important and effective factor in controlling and reducing stress. Nurses 'praying has also been demonstrated to play a role in reducing job stress and increasing nurses' comfort and relaxation (Achour et al., 2019, 2021). Spirituality promotes personal faith and reduces stress and depression among nurses. Also, performing religious practices had a protective effect against occupational stress among registered Nurses (Batalla et al., 2019). It has been found that religious coping can moderate the effect of stress on outcomes of behavioral disorders and lead to maintenance and protection of communities health against severe crises, such as the COVID-19 pandemic (Pirutinsky et al., 2021).

A study conducted in Turkey found that participants preferred to pray to manage stress (Ozdemir et al., 2021). Also, the results of a study performed in Korea showed that praying prevents people from experiencing negative stressors and facilitates emotionally and cognitively processing (Parks-Stamm et al., 2020). Positive religious coping behaviors are based on solid, trustful, and safe relation with God. In contrast, negative religious coping reflects a less secure relationship with God and spiritual tensions (Charzyńska, 2015). In explaining the results mentioned above and based on Koenig's view, it can be said that spirituality, spiritual beliefs and practices cause a positive attitude toward the world in a person and help him in the face of unpleasant life events, such as disability or illness. It can also help him improve his quality of life by creating motivation and energy in person. This issue causes an increased tolerance and acceptance of unchangeable conditions. This is especially important in many critical cases where science cannot help the individual (Ibrahim et al., 2020; Koenig, 2020). Nurses worldwide engage in religious activities and spiritual behaviors to overcome stress and reduce negative consequences of work stress, but they reveal differences in techniques employed. Thus, spirituality may equip people with strategies that may effectively cope with stress.

Our findings suggested that education programs regarding strengthening spiritual coping and integrating them into care processes can help to moderate the effect of occupational stress among nurses and EMS staff. Studies about the spiritual coping of healthcare workers to decrease the stress caused by the COVID-19 pandemic are limited. However, we identified different types of spiritual strategies for coping with occupational stress among ED nurses and EMS staff in Ardabil Province during the COVID-19 pandemic. 


\section{Limitations}

The present study had some limitations. Firstly, this study was conducted on emergency healthcare workers, therefore, this study had a lack of generalizability. Additionally, the COVID-19 pandemic induces various unprecedented effects on all aspects of life, then, it is important to interpret our findings cautiously. Many quantitative designs have been used to study spirituality in nurses, hence, studies with qualitative designs are required to complement our work. Qualitative studies can provide deeper insights into these concepts. Moreover, low variance $(11 \%$ and $6 \%$, respectively) for the positive and negative spiritual coping causes limitation in the interpretation of outcomes.

\section{Conclusion}

This study is the first to evaluate the spiritual coping status of Iranian ED nurses and EMS staff working on the frontline against the COVID-19 pandemic. Variables such as workplace, service location, and type of employment were significant predictors of positive spiritual coping, and variables of high age, overtime, and marital status were predictors of negative spiritual coping. Additionally, the positive religious strategy was the main coping method followed by positive social, personal, and environmental strategies for coping with stress, respectively. Strengthening positive spiritual coping, improving negative spiritual coping by religious counseling, and strengthening one's relationship with God help moderate occupational stress among healthcare workers, especially during this COVID19 crisis. Then, providing an appropriate spirituality approach for healthcare workers in the workplace will be valuable. Our findings suggest that health managers and politicians should pay attention to enhancing staff's spiritual values and increasing their job satisfaction through providing resources for training spiritual coping strategies to ED nurses and EMS staff such as in-house workshops around spirituality.

Supplementary Information The online version contains supplementary material available at https://doi. org/10.1007/s10943-022-01523-7.

Acknowledgements We would like to thank all the participants of this study.

Author Contributions Data collection and field work contributed AHS. Acquisition, analysis, or interpretation of data contributed AHS and AM. Statistical analysis contributed NM. Drafting of the manuscript contributed AM. Critical revision of the manuscript for important intellectual content contributed all authors. All authors read and approved the final manuscript.

Funding No funding.

\section{Declarations}

Conflict of interest The authors responsibly declare that they have no conflicting interests. 
Ethical Approval The protocol of the current study has been approved by the Ardabil University of Medical Sciences and has received all the necessary permits for its preparation. (Research Ethics Committee, Ardabil University of Medial Sciences No.: IR. ARUMS REC.1399.459).

Consent to Participate The paper-based questionnaire of the study ensured voluntary participation, participants' consent, the provision of information regarding the purpose of the survey as well as confidentiality and anonymity.

\section{References}

Achour, M., Binti Abdul Ghani Azmi, I., Bin Isahak, M., Mohd Nor, M. R., \& Mohd Yusoff, M. Y. Z. (2019). Job stress and nurses well-being: Prayer and age as moderators. Community Mental Health Journal, 55(7), 1226-1235. https://doi.org/10.1007/s10597-019-00410-y

Achour, M., Muhamad, A., Syihab, A. H., Mohd Nor, M. R., \& Mohd Yusoff, M. Y. Z. (2021). Prayer moderating job stress among Muslim nursing staff at the university of Malaya medical centre (UMMC). Journal of Religion and Health, 60(1), 202-220. https://doi.org/10.1007/ s10943-019-00834-6

Albaqawi, H. M., Alquwez, N., Almazan, J. U., Alharbi, S. M., Catimbang, C. C., Rivera, P. P., \& Cruz, J. P. (2019). Workplace spiritual climate and its influence on nurses' provision of spiritual care in multicultural hospitals. Religions, 10(2), 118. https://doi.org/10.3390/rel10020118

Batalla, V. R. D., Barrameda, A. L. N., Basal, J. M. S., Bathan, A. S. J., Bautista, J. E. G., Rebueno, M. C. D. R., \& Macindo, J. R. B. (2019). Moderating effect of occupational stress on spirituality and depression of Registered Nurses in tertiary hospital: A structural equation model. Journal of Advanced Nursing, 75(4), 772-782. https://doi.org/10.1111/jan.13856

Bentzen, J. (2020). In crisis, we pray: Religiosity and the COVID-19 pandemic. CEPR Centre for Economic Policy Research. https://cepr.org/active/publications/discussion_papers/dp.php?dpno= 14824.

Charzyńska, E. (2015). Multidimensional approach toward spiritual coping: Construction and validation of the spiritual coping questionnaire (SCQ). Journal of Religion and Health, 54(5), 16291646. https://doi.org/10.1007/s10943-014-9892-5

Chow, S. K., Francis, B., Ng, Y. H., Naim, N., Beh, H. C., Ariffin, M. A. A., Yusuf, M. H. M., Lee, J. W., \& Sulaiman, A. H. (2021). Religious coping, depression and anxiety among healthcare workers during the COVID-19 pandemic: A Malaysian perspective. Healthcare, 9(1), 79. https://doi. org/10.3390/healthcare9010079

Del Castillo, F., del Castillo, C. D., \& Corpuz, J. C. (2021). Dungaw: Re-imagined religious expression in response to the COVID-19 pandemic. Journal of Religion and Health, 60(4), 2285-2305. https://doi.org/10.1007/s10943-021-01266-x

DeRossett, T., LaVoie, D. J., \& Brooks, D. (2021). Religious coping amidst a pandemic: Impact on COVID-19-Related anxiety. Journal of Religion and Health, 60, 3161-3176. https://doi.org/10. 1007/s10943-021-01385-5

Doraiswamy, I. R., \& Deshmukh, M. (2015). Workplace spirituality and role among nurses. IOSR Journal of Nursing and Health Science, 4(3), 6-13. https://doi.org/10.9790/1959-04430613

Eslami Akbar, R., Elahi, N., Mohammadi, E., \& Fallahi Khoshknab, M. (2015). What strategies do the nurses apply to cope with job stress? A qualitative study. Global Journal of Health Science, 8(6), 55-64. https://doi.org/10.5539/gjhs.v8n6p55

Farshadnia, E., Borji, M., Sadighpour, M., Khorrami, Z., \& Memaryan, N. (2020). The role of demographic factors in the spiritual health of the students of Iran university of medical sciences. International Journal of Behavioral Sciences, 14(1), 1-5. https://doi.org/10.30491/ijbs.2020.199649. 1127

Habibian, N., Ahmadi, R., Vashian, A., Mortazavi, S. M., \& Dadkhah-Tehrani, T. (2015). Investigating the correlation between the life and religious attitudes with psychological well-being in nurses working in health centers at Qom universities of medical sciences in 2014. Mediterranean Journal of Social Sciences, 6(6S4), 168.

Hassankhani, H., Taleghani, F., Mills, J., Birks, M., Francis, K., \& Ahmadi, F. (2010). Being hopeful and continuing to move ahead: Religious coping in Iranian chemical warfare poisoned veterans, 
a qualitative study. Journal of Religion and Health, 49(3), 311-321. https://doi.org/10.1007/ s10943-009-9252-z

Huang, X., Wei, F., Hu, L., Wen, L., \& Chen, K. (2020). Epidemiology and clinical characteristics of COVID-19. Archives of Iranian Medicine, 23(4), 268-271. https://doi.org/10.34172/aim.2020.09

Ibrahim, M. A., Isa, K. Q., Haji-Idris, H.-A., Nawi, S.-H., Teo, Y. C., Abdul Rahman, H., \& AbdulMumin, K. H. (2020). Spiritual coping with stress among emergency and critical care nurses: A cross-sectional study. Community Mental Health Journal, 56(2), 287-293. https://doi.org/10. 1007/s10597-019-00486-6

Jannati, Y., Mohammadi, R., \& Seyedfatemi, N. (2011). Iranian clinical nurses' coping strategies for job stress. Journal of Occupational Health, 53(2), 123-129. https://doi.org/10.1539/joh.O10015

Khodayarifard, M., Mansouri, A., Besharat, M. A., \& Gholamali Lavasani, M. (2019). The standardization of spiritual coping questionnaire in student population. Journal of Fundamentals of Mental Health, 21(4), 221-231. https://doi.org/10.22038/jfmh.2019.14397

Koenig, H. G. (2020). Maintaining health and well-being by putting faith into action during the COVID-19 pandemic. Journal of Religion and Health, 59(5), 2205-2214. https://doi.org/10. 1007/s10943-020-01035-2

Lucchetti, G., Góes, L. G., Amaral, S. G., Ganadjian, G. T., Andrade, I., de Araújo Almeida, P. O., \& Manso, M. E. G. (2020). Spirituality, religiosity and the mental health consequences of social isolation during Covid-19 pandemic. The International Journal of Social Psychiatry. https://doi. org/10.1177/0020764020970996

Mahmood, Q. K., Jafree, S. R., Sohail, M. M., \& Akram, M. B. (2021). A cross-sectional survey of Pakistani Muslims coping with health anxiety through religiosity during the COVID19 pandemic. Journal of Religion and Health, 60(3), 1462-1474. https://doi.org/10.1007/ s10943-021-01218-5

Ozbasaran, F., Ergul, S., Temel, A. B., Aslan, G. G., \& Coban, A. (2011). Turkish nurses' perceptions of spirituality and spiritual care. Journal of Clinical Nursing, 20(21-22), 3102-3110. https://doi. org/10.1111/j.1365-2702.2011.03778

Ozdemir, A., Serin, E. K., \& Savas, M. (2021). The Relationship between the stress perceived by the intensive care patient's relatives with their religious attitudes and behaviors: Turkey sample. Journal of Religion and Health, 60(2), 752-763. https://doi.org/10.1007/s10943-020-01116-2

Pargament, K., Feuille, M., \& Burdzy, D. (2011). The Brief RCOPE: Current psychometric status of a short measure of religious coping. Religions, 2, 51-76. https://doi.org/10.3390/rel2010051

Parks-Stamm, E. J., Pollack, J. S., \& Hill, D. R. (2020). The impact of prayer direction on emotional and cognitive responses to personal problems. Psychology of Religion and Spirituality, 12(4), 471-474. https://doi.org/10.1037/rel0000280

Pirutinsky, S., Cherniak, A. D., \& Rosmarin, D. H. (2021). COVID-19, religious coping, and weight change in the orthodox Jewish community. Journal of Religion and Health, 60(2), 646-653. https://doi.org/10.1007/s10943-021-01196-8

Rajabipoor Meybodi, A., \& Mohammadi, M. (2021). Identifying the components of spirituality affecting the resilience of nurses. Journal of Nursing Management, 29(5), 982-988. https://doi.org/10. 1111/jonm.13235

Rias, Y. A., Rosyad, Y. S., Chipojola, R., Wiratama, B. S., Safitri, C. I., Weng, S. F., Yang, C. Y., \& Tsai, H. T. (2020). Effects of spirituality, knowledge, attitudes, and practices toward anxiety regarding COVID-19 among the general population in INDONESIA: A cross-sectional study. Journal of Clinical Medicine, 9(12), 3798. https://doi.org/10.3390/jcm9123798

Ribeiro, M., Caldeira, S., Nunes, E., \& Vieira, M. (2021). A commentary on spiritual leadership and workplace spirituality in nursing management. Journal of Nursing Management, 29(3), 602-605. https://doi.org/10.1111/jonm.13196

Robards, J., Evandrou, M., Falkingham, J., \& Vlachantoni, A. (2012). Marital status, health and mortality. Maturitas, 73(4), 295-299. https://doi.org/10.1016/j.maturitas.2012.08.007

Ronaldson, S., Hayes, L., Aggar, C., Green, J., \& Carey, M. (2012). Spirituality and spiritual caring: Nurses' perspectives and practice in palliative and acute care environments. Journal of Clinical Nursing, 21(15-16), 2126-2135. https://doi.org/10.1111/j.1365-2702.2012.04180.x

Shakeri, K., Jafari, M., Khankeh, H., \& Seyedin, H. (2019). History and structure of the fourth leading emergency medical service in the world; a review article. Archives of Academic Emergency Medicine, 7(1), e17. https://doi.org/10.22037/aaem.v7i1.327 
Szałachowski, R., \& Tuszyńska-Bogucka, W. (2021). "Dies Irae?” The role of religiosity in dealing with psychological problems caused by the COVID-19 pandemic-studies on a polish sample. Religions, 12(4), 267. https://www.mdpi.com/2077-1444/12/4/267.

Yang, J., \& Shin, S. (2016). A study of relationship between death perception, spiritual well being and terminal care stress of geriatric hospital nurses. The Korea Academia-Industrial Cooperation Society, 17(6), 510-520. https://doi.org/10.5762/KAIS.2016.17.6.510

Publisher's Note Springer Nature remains neutral with regard to jurisdictional claims in published maps and institutional affiliations.

\section{Authors and Affiliations}

\section{Aghil Habibi Soola ${ }^{1} \cdot$ Naser Mozaffari $^{1} \cdot$ Alireza Mirzaei $^{2}$}

Aghil Habibi Soola

habibiarums@gmail.com

Naser Mozaffari

naser.m51@gmail.com

1 Department of Nursing, School of Nursing and Midwifery, Ardabil University of Medical Sciences, Ardabil, Iran

2 Department of Emergency Nursing, School of Nursing and Midwifery, Ardabil University of Medical Sciences, Ardabil, Iran 